\author{
NINA PIELACIŃSKA \\ Universidade Adam Mickiewicz, Poznań \\ ninapielacinska@gmail.com
}

\title{
ENTRE INTERNACIONALIZAÇÃO E ESQUECIMENTO: O FENÓMENO DO FADO E DA COPLA ANDALUZA DURANTE A DITADURA
}

\begin{abstract}
Nina Pielacińska, Entre internacionalização e esquecimento: o fenómeno do Fado e da Copla andaluza durante a ditadura [Somewhere between internationalization and oblivion: pathways of Fado and Copla andaluza under dictatorship], Studia Romanica Posnaniensia, Adam Mickiewicz University Press, Poznań, vol. XL/1: 2013, pp. 29-41. ISBN 978-83-232-2542-3. ISSN 0137-2475. eISSN 2084-4158.

The main objective of the article is to analyze the socio-political situation and the other factors determining the development of music types such as Fado and Copla during the dictatorship times in Spain and Portugal. These genres were used for the political and propaganda purposes. Many artists like for example Lola Flores or Amália Rodrigues have become famous exactly during the regime times, however, their real success can be measured with the arrival of democracy. Copla which represents the image of Franco's Spain has been replaced by some new music genres and it has never been reborn as it had happened in the case of Fado. This Portuguese music genre was a subject of changes starting from 60's. Significant modifications have been done in both: lyrics and accompaniment; Fado survived the anti-Fado period (1974-1975) and from the 90's until present experiences an ongoing rebirth. Studies on Fado's and Copla's popularity may also prove to be crucial in understanding the phenomenon of transculturalism. All the factors that boosted the process of internationalization of this music in the twenty-first century should become an object of a multifaceted analysis.
\end{abstract}

Keywords: Fado Music, Copla andaluza, dictatorship, propaganda, internationalization.

\section{INTRODUÇÃO}

O objetivo principal do presente trabalho é pronunciarmo-nos acerca do tema da música espanhola e portuguesa durante as respetivas ditaduras e verificar até que ponto a popularidade de géneros como o Fado ou a Copla se deve ao apoio dos regimes ditatoriais e por que com a chegada da democracia houve mudanças tão significativas e diferentes na sua percepção. Em primeiro lugar expliquemos o contexto histórico, ou seja, a formação dos novos governos depois da Guerra Civil espanhola e do golpe militar de 1926 em Portugal e apresentaremos brevemente a situação sociopolítica dos "novos países". Analisaremos também o papel dos acima mencionados géneros e exporemos duas personagens que obtiveram muito sucesso durante o dito período: Lola Flores e Amália Rodrigues. 
Apesar de existir uma grande quantidade de investigações sobre o tema, há que ter em conta que a crítica retrospectiva e a necessidade de uma ação historiográfica só foram julgadas necessárias a partir dos anos 60 . Na primeira década das ditaduras, a imagem da arte era bastante restringida. Os anos setenta trouxeram-nos uma imagem oposta à anterior, situando-se contra a historiografia oficial da arte. Contudo, as particulares formas de visceralidade e a ausência de estudos sobre o tema no início das ditaduras não nos permitem levar a cabo revisões históricas claras, e até hoje em dia causam certos paradoxos.

\section{AS FUNÇÕES DA MÚSICA DURANTE A DITADURA}

Tomando em conta a importância da relação estado-arte para melhor entender a situação cultural da sociedade, neste trabalho abordamos o tema da função da música como instrumento de luta e propaganda política. Em primeiro lugar, é conveniente destacar como uma das características mais significativas a função de dotar identidade coletiva à população, unifica-la como podemos ver:

La nación debe quedar limitada en todas las dimensiones culturales y sensoriales del individuo.

La nación no puede ser sólo visual, debe ser también sonora. La música, desde sus bases populares, nos otorga la oportunidad de construirnos una nación sonora, una patria musical a la cual yo reconozca y en la que yo me reconozca. Cada nación hace (supuestamente) su música, por lo que, recíprocamente, la música hace nación. (Muñiz Velázquez, 1998: 344)

Seguindo este caminho, veremos o importante que é dar coesão à sociedade através da música. As canções compostas pelo governo e cantadas pelos membros de um grupo, de uma fação ou de uma nação evocam solidariedade e forjam união entre os indivíduos. Talvez, por isso, a música estava sempre presente nas manifestações públicas e reuniões militares. Como exemplo temos também os hinos dos países, das regiões, de cidades ou grupos sociais. As canções e melodias produzem imagens, falam de feitos importantes (desde o ponto de vista político), de personagens famosos e desta forma apresentam-se às pessoas como mais palpáveis, más acessíveis. Além de que, fortalecem o governo, apoiam e validam as instituições já que também legitimam a ordem. Outro fator significativo é o de diminuir a capacidade crítica. Segundo lemos em Fromm:

Los métodos de propaganda política tienen sobre el votante el mismo efecto que los de la propaganda comercial sobre el consumidor, ya que tienden a aumentar su sentimiento de insignificancia. La repetición de eslóganes y la exaltación de factores que nada tienen que ver con las cuestiones discutidas, inutilizan sus capacidades críticas. (1947: 136)

Durante as ditaduras, a incorporação da mensagem propagandística multiplica ainda mais esse sentimento de insignificância, já que o autor do texto se referia no seu livro à democracia. O sistema totalitário, elogiando e sublinhando o seu programa político na letra das canções evita discussões e entra no terreno do inquestionável. 
Funciona como se fosse um mito na publicidade (Huici Módenes, 1996) que dá caráter coletivo, coage e persuade ao mesmo tempo. Também não nos podemos esquecer da diversão e entretenimento que nos proporciona a música. Em muitos casos, a situação dos países em que se estabeleceu um regime ditatorial era muito difícil. Uma sociedade miserável, degradada, privada de dignidade e honra, teve que recuperar-se e retomar a vida quotidiana a partir do que havia restado e daquilo que o novo poder considerava adequado e possível. Tinha que se disfarçar a miséria física e as carências materiais das pessoas. Para que assim fosse, o governo tentou promover uma série de associações falsas ou verdadeiras, mas sempre positivas e relacionadas com a situação do país. O fato de que as pessoas se entretenham e se esqueçam dos problemas transporta consigo uma carga favorável e benéfica e forma assim uma das ferramentas mais eficientes de propaganda. Ao longo deste artigo, dedicaremos uma parte do estudo ao elenco de novos mitos e novos nomes que surgiram em Espanha e Portugal de modo a analisar as funções mais próprias e características das ditaduras cuja obrigação era a de simular uma realidade social estável, feliz e normalizada, apagar o passado, esconder a pobreza e olhar para o futuro.

\section{A SITUAÇÃO SOCIO-POLÍTICA EM ESPANHA E EM PORTUGAL}

Para falar do mecanismo da música como propaganda na Espanha de Franco, parece conveniente apresentar os acontecimentos políticos que levaram à formação do novo governo nos anos trinta. Como se sabe, no dia 18 de julho de 1936 em Espanha estalou a Guerra Civil. Por ordem do general Francisco Franco, um setor do exército revoltou-se para derrubar o Governo legal e democrático da Segunda República Espanhola que, desde 1931, tinha sucedido à monarquia. Os insurgentes ganharam nas zonas onde foram mais votadas as candidaturas de direita nas eleições de fevereiro. Graças ao sucesso obtido, no dia 1 de outubro, Franco foi nomeado Chefe de Estado e formou o seu governo na cidade de Burgos. A partir daí, os seus exércitos deixaram de ser revoltosos, autodenominando-se "nacionalistas", em referência ao seu propósito de unificar o país debaixo de um governo central que enaltecesse a pátria castelhana. As forças republicanas defenderam o governo democrático em luta contra os rebeldes até à queda da última capital, Múrcia. No dia 1 de abril de 1939, o general Francisco Franco declarou oficialmente que a Guerra Civil tinha terminado, deixando a Espanha sob o regime franquista. Assim começava um pós-guerra difícil, porque o final da guerra não significou paz e reconciliação. O próximo objetivo era gerir a vitória e torná-la duradoura. Em relação a isto, o Caudillo iniciou a delimitação do Estado, no qual o partido único era a Falange Espanhola Tradicionalista e das Juntas de Ofensiva Nacional Sindicalista, denominado também como "Movimento Nacional". Ao estabelecer-se em todo o país, o governo de Franco, iniciou uma etapa de atrozes represálias contra os vencidos. Só se salvaram aqueles que optaram pelo 
exilio. Franco, apoiado pelo Exército e pela Igreja, impôs ordem moral. A repressão funcionava como um instrumento para delimitar e unificar a zona franquista, enquanto que o terror tornava possível o fortalecimento do regime. Por outro lado, existia uma purga que eliminava pessoas dissidentes, privando-os do seu trabalho com base numa revisão da trajetoria da vida privada e pública dos anos republicanos. Tendo em conta a situação política dos anos 40 e dos mecanismos que funcionavam durante esse período, os espanhóis depararam-se com um panorama de controlo total por parte de instituições como as das prefeituras provinciais de propaganda. O processo de comunicação política (entendido como as relações entre o poder, os meios de comunicação e a cidadania) deu origem a um controlo rígido dos meios de comunicação social, confundindo-se consequentemente, a propaganda com a informação ${ }^{1}$.

O novo regime ditatorial estava tão regulamentado que cada manifestação contrária ao poder era castigada e nenhum tipo de oposição podia manifestar-se. Criou-se a Delegação do Estado para a Imprensa e Propaganda, cujo objetivo era a purificação de livrarias e bibliotecas, o controlo de projeções y produções cinematográficas, a estrutura do complexo mecanismo de censura e a destruição de todo aquilo que atentava contra a religião católica e a unidade da pátria. As alterações mais importantes aparecem apenas com o fim da ditadura, no dia 20 de novembro de 1975, com a morte de Franco e a chegada da democracia.

Para tentar compreender a especificidade da música do mundo português, temos de mencionar a personagem de António de Oliveira Salazar que foi a figura central do Estado Novo e deixou uma marca muito forte na vida pública. Portugal no início do século XX estava à beira da ruína económica e social. Nesse período, o golpe começado pelas forças armadas, em 1926 instaurou em Portugal uma ditadura militar. A instabilidade política e os problemas económicos fizeram agravar o défice orçamental e a dívida externa do país. Foi neste contexto que o general Óscar Carmona foi eleito Presidente da República em 1928 e convidou António Salazar para ministro das finanças. Este tornou-se primeiro-ministro de Portugal em 1932, função durante a qual sustentou o país em regime ditatorial por 41 anos. A nova Constituição foi promulgada em Abril de 1933 e pôs fim ao período da ditadura militar. Desde então, iniciou-se um novo período que o próprio Salazar chamou de Estado Novo.

A sua subida ao poder derivou da vontade em criar um estado forte que assentasse essencialmente no reforço do poder executivo. Assim, aboliam-se os sindicatos livres e substituía-se um pluralismo partidário por um partido único. Uma das principais características do país sob o novo regime salazarista foi, em primeiro lugar, preservar os valores tradicionais como o triunvirato Deus, Pátria e Família, para formar uma sociedade com bons princípios morais. Também é importante destacar o imperialismo colonial, (pretendia manter vastos territórios dispersos por vários continentes)

\footnotetext{
${ }^{1}$ Durante a Guerra Civil e também aquando do regime, as autoridades franquistas aplicaram a censura prévia a cada setor da vida cultural. Todas as publicações periódicas tinham que aceitar a inclusão de artigos oficiais sujeitos à censura militar.
} 
nacionalismo económico, o culto de um chefe paternal, um líder com boas maneiras, que não aceitava nem se autonomeava com alcunhas tal como Mussolini (duce) ou Franco (caudillo). Salazar foi profundamente conservador, católico, nacionalista e antiparlamentar, rejeitado também o comunismo e o liberalismo. Segundo os princípios proclamados em 1936:

Às almas dilaceradas pela dúvida e o negativismo do século procurámos restituir o conforto das grandes certezas. Não discutimos Deus e a virtude; não discutimos a Pátria e a sua História; não discutimos a autoridade e o seu prestígio; não discutimos a família e a sua moral; não discutimos a glória do trabalho e o seu dever. (Mattoso, 1998: 260)

Os direitos dos cidadãos foram muito limitados. Em 1926 tinha sido instituída a censura aos meios de comunicação social, teatro, cinema, rádio e televisão. Ela visava supervisionar todos os assuntos políticos, religiosos e militares. O poder era de tal modo repressivo, que as liberdades individuais, de imprensa, de reunião e direito à greve foram restringidas. Operava a Polícia Internacional de Defesa do Estado (PVDE, mais tarde PIDE), que foi uma polícia política criada em 1933 que reprimia de acordo com critérios de selectividade inventados pelo governo, impedia escândalos de vária ordem e a divulgação de actividades contra o governo. A PIDE utilizava a tortura física e psicológica para obter confissões e denúncias, mandava prender opositores ao regime, violava correspondência e invadia residências. Possuía ainda uma grande rede de informadores nas escolas, no trabalho e nos centros de convívio. A influência de Salazar dominava todos os sectores da vida portuguesa, de modo que tudo era controlado.

Quando se inicia a Segunda Grande Guerra Mundial, Portugal declara imediatamente a sua neutralidade. A posição portuguesa foi determinada pela intransigente defesa daquilo que o Governo entendia como "interesse português", conforme com a sua vocação essencialmente ultramarina, pelo que o interesse português era o de afastar-se o mais possível da política europeia e do conflito. Esta gestão da neutralidade portuguesa trouxe-lhe, no final do conflito, os benefícios da paz sem ter de pagar o preço da guerra. O país foi uma das poucas zonas de paz no mundo e serviu de refúgio a muitos foragidos de várias proveniências. Um desses refugiados foi o arménio Calouste Gulbenkian, que se mudou para Portugal e deixou a sua fortuna para a constituição da Fundação que se tornou uma das mais notáveis instituições ao serviço da cultura no país.

O fim da Segunda Guerra Mundial significou o triunfo das democracias como formas de governo na Europa Ocidental e condenou o totalitarismo. A partir do pósguerra, Salazar sentiu necessidade de realizar certas reformas. As eleições de 1945 foram fraudulentas e manipuladas, e como resultado tivemos o regime por mais de 30 anos. Apesar da longevidade da ditadura, tolerada pelos países democráticos, Portugal permaneceu isolado do resto da Europa, por motivos de orientação política, mas também por razões económicas, sociais e culturais. Seguía sendo un país atrasado, rural e com índices de analfabetismo muito elevados e acima de tudo, com um grave pro- 
blema colonial. Salazar sempre se opôs à independência das colónias, o que provocou uma longa e ruinosa guerra colonial que agravou ainda mais os problemas da nação. Esta situação isolou ainda mais o regime e precipitou o fim da ditadura que chegou ao fim em 25 de Abril de 1974, derrubada por uma sublevação militar popularmente conhecida como "Revolução dos Cravos".

\section{A COPLA ANDALUZ COMO SÍMBOLO DE IDENTIDADE NACIONAL}

Depois de se formar o novo governo surgiu a necessidade de criar também outro tipo de arte que fizesse parte da nova cultura do país e que se relacionasse com o Estado. Segundo diversas opiniões acerca do tema, o franquismo, tal como outros regimes totalitários, tentou converter a cultura em política ${ }^{2}$. A arte foi, sem qualquer sombra de dúvida, propagandística, e de centralismo castelhano. Franco serviu-se da arte de massas difundida através dos meios de comunicação que estavam estreitamente controlados. Os espanhóis tinham que elogiar ou calar a "verdade" publicada no Boletin Oficial do Estado. Como consequência de não poderem manifestar as suas opiniões livremente, a maioria dos humanistas, filósofos, cantores, poetas e escritores ${ }^{3}$ exilaramse em países como França, México, Argentina ou Estados Unidos. Outros estiveram presos, como é o caso de Miguel Hernández, ou foram assassinados (Federico García Lorca). Como resultado desta política, houve um grave atraso cultural que de algum modo foi encoberto por uma arte populista. Uma boa parte das produções eram de baixa ou mesmo nula qualidade artística, mas constituíam o único aspeto que o Estado queria mostrar de Espanha no estrangeiro. $O$ onipresente processo de aculturação tentava substituir a cultura da República e impor o tradicional e folclórico que trazia à mente a imagem de una Espanha alegre, espirituosa, festiva e com perspectivas de futuro. Assim temos como símbolos da nova Espanha os touros, a copla, a Andaluzia como típica terra espanhola e o folclore. Formou-se uma arte carecida de problemas políticos e preocupações intelectuais, mas ao mesmo tempo de grande popularidade e difusão entre o povo, com o objetivo principal de mascarar o fracasso e desilusão da sociedade daqueles tempos.

Indubitavelmente, o género que manifestava todas estas características foi a canção nacional, ou seja, a canção espanhola, que a princípio foi construída sobre a lírica tradicional e a tonadilla. $\mathrm{O}$ seu desenvolvimento pleno teve lugar graças a letristas como Antonio Quintero, Valerio e sobretudo Rafael de León, tendo em conta que quase todos eram partidários da ordem política estabelecida. Com efeito, temos a canção nacional que «se aplica a glosar todo lo oficialmente peculiar español: in-

\footnotetext{
${ }^{2}$ «Como en otros regímenes fascistas, en el español la cultura oficial se convirtió en propaganda y en instrumento de una política de dominación» (Llorente Hernández, 1995: 45).

${ }^{3}$ Rafael Alberti, Luis Cernuda, Jorge Guillén, Juan Ramón Jiménez, María Teresa León, Emilio Prados o Pedro Salinas.
} 
dividualismo (en oposición al colectivismo), peculiaridades raciales, exaltación del destino histórico, excelencias de todo lo nuestro» (Vázquez Montalbán, 1972). «El concepto de la canción popular no es, precisamente, la del folklore auténtico del pueblo, conservado a través de los tiempos, sino los remedos, más o menos profesionales» (Herrero, 1984: 27).

A Copla andaluza, considerada como a mais famosa e típica canção de Espanha, e ao mesmo tempo, um dos palos flamencos, bateu recordes de audiência a partir dos anos 40 até à metade dos 60 . Como forma poética é uma estrofe de quatro ou oito versos de arte maior ou menor, geralmente octossílabos. Devido à regularidade dos versos nas coplas, tendem a rimar. Nos anos 40 , e até à metade dos 50, a maioria dos artistas começou a interpretá-la para ganhar o apreço e a simpatia das autoridades. Os pioneiros do género que apareceram em cena foram Concha Piquer, Estrellita Castro, Imperio Argentina, Miguel de Molina e Juanita Reina. Posteriormente apareceram muitas outras figuras «que aprovecharon la comercialidad de la copla y abandonaron el flamenco para hacer incursiones en ésta. Realmente, el mundo de la copla y el flamenco se tocan en muchas ocasiones» (Boyero Gómez, 2000). Neste último caso, devemos mencionar Pepe Marchena, Pepe Pinto, Juanito Valderrama, La Niña de los Peines e Angelillo. Outro grupo consiste numa série de artistas que enriqueceram a cena com os seus bailes e actuações, mas que apareceram mais adiante, como una "novidade". Entre eles destacam-se Lola Flores e Manolo Caracol, Carmen Morell y Pepe Blanco, Carmen Sevilla, Antonio Molina, que originou uma revolução na forma de cantar, etc. Todos tiveram um papel muito significativo para os espanhóis, popularizando a copla através da rádio, dos filmes, de pequenos espectáculos nos cafés cantantes e nas grandes produções teatrais.

Sob o governo franquista era quase impossível desenvolver outro tipo de arte que não a aprovada pelo regime. Franco desenvolveu um tipo de música condicionada por uma determinada ideia das peculiaridades espanholas. Para entender melhor este fenómeno atentemos à figura de Lola Flores, que durante essa época era uma das personagens mais populares, mais importantes e mais significativas. É consensual que obteve sucesso durante décadas. Começando pelas canções populares, que trauteavam milhões de pessoas, passando pelos espectáculos teatrais, os programas de rádio o a imprensa cor-de-rosa, e terminando com a bastante ampla coleção de filmes que protagonizou. Os espanhóis experimentaram uma intensa corrente de simpatia em relação ao modo de ser e de se expressar que lhe eram tão próprios. Segundo afirmam alguns críticos, diversas gerações estabelecidas nos anos quarenta sentiam-se representadas por ela. Lola Flores foi durante muitos anos o retrato idealizado de uma certa Espanha. Infelizmente, temos que dar-nos conta de que estamos falando de um país no qual se substituía o trabalho cerebral pela improvisação engenhosa e onde eram mais apreciadas as gracias de la picaresca do que a indústria ou a ciência.

Lola assegurava que não era política, e muito menos franquista. Por um lado poder dar-se-lhe razão, já que não elogiava ou endeusava a figura do Caudillo, como 
faziam muitos personagens públicos. Mas devido à sua atitude, atividades e trabalho, fez muito pelo regime. Como se sabe, não se pode viver, trabalhar, criar, atuar e permanecer no topo da popularidade dentro de um país dominado por um regime ditatorial sem saber nada de política. Para sobreviver à censura e a leis severas tinha que se colaborar com as autoridades, de forma consciente ou não. Lola manteve muito boas relações com as autoridades, que lhe outorgaram todo o tipo de condecorações, e favoreceram a sua carreira dentro e fora do país. Até meados dos anos 70 não parou de atuar. Poderia afirmar-se que Franco simplesmente deixou-a fazer o seu trabalho, mas é necessário clarificar de que tipo de trabalho estamos a falar. Evidentemente, Lola Flores, falseava a imagem da Espanha dos anos quarenta como mandava el Caudillo, assistia às festas da Granja de San Ildefonso ${ }^{4}$ e inclusivamente sentia-se orgulhosa de ter recebido o convite. No entanto, com as suas atividades apoiava as autoridades e aproveitava-se para seu próprio benefício. Dizia que Franco não lhe deu nada, porque nunca lhe pediu nenhum carro nem jóias como faziam os seus amigos artistas daquele tempo. A única coisa que the deve é o Lazo de Dama de Isabel la Católica ${ }^{5}$ que recebeu no ano de 1962 por ser a melhor embaixadora de Espanha. Mas o seu trabalho poderia também ser definido "trabalho político", e isso era-lhe criticado muitas vezes. A "Lola Nacional", talvez de forma inconsciente, levava ao estrangeiro a mensagem do regime franquista através de uma falsa imagem de Espanha. Uma das canções em que esta situação se apresenta foi escrita por Quintero, León e Quiroga, intitulava-se ¡Ay España, España mía!:

De la España vieja de los reyes moros

os traigo recuerdos en una canción,

que huele a claveles y a tarde de toros,

que sabe a romance de menta y limón.

Sevilla me dijo: "Lola,

dile al pueblo americano

que está dentro de mí"

¡Ay España, España mía! [...]

Si de cerca te quería,

De lejos te quise más. (García-Garzón, 1990: 112)

${ }^{4}$ Trata-se de uma localidade situada na província de Segovia, que durante a época franquista estava fortemente relacionada com as celebrações do 18 de julho. Era a data da "iniciação do glorioso levantamento" de 1936, a sublevação militar dirigida contra o governo da Segunda República Espanhola que terminou com a subida ao poder do regime franquista.

5 Tratava-se de uma condecoração com muita história e tradição. Originalmente criada por Fernando VII, mediante Real Decreto de 24 de março de 1815, com o desejo de « recompensar la acrisolada lealtad, el zelo y patriotismo, desprendimiento, valor y otras virtudes, que tanto los individuos de la milicia como los de todas las clases y gerarquías del Estado han mostrado y mostraren en adelante, en favor de la defensa y conservación de aquellos remotos países» (Stair Sainty, 1997). 


\section{A REDESCOBERTA E RENOVAÇÃO DO FADO}

No caso de Portugal, ao longo da década de 1930 e até ao final da II Guerra Mundial o regime não era consciente das funções da música, daí o Fado foi quasi ausente ou teve uma presença pouco significativa. Ou seja, o governo tolerava a prática do Fado (sujeito a uma censura rigorosa), mais não valorizava o género e tendia a restringir a sua utilização em programas oficiais de impacte social. Esta política do governo vai mudar a partir do pós-guerra quando os portugueses começam a perder a confiança vendo como funcionam as novas democracias europeias. Salazar precisava de promover a cultura de massas como possível barreira para a entrada de elementos externos. Neste novo contexto, o governo percebeu a importancia do género que a partir do século XIX foi presente no mundo português. A partir de agora, Salazar tentava incorporar o Fado no seu discurso cultural populista e utilizá-lo de modo propagandístico.

Portanto, os anos 40, 50 e 60 do século XX formam a época de ouro do género. As casas de Fado se multiplicam, aparecem cantadores e cantadeiras atraídos pela grande popularidade e a possibilidade de uma carreira profissional. As empresas começam a editar um número significativo de discos de Fado, a rádio difunde o género a nivel nacional na medida em que os portugueses decidem criar a iniciativa anual da Grande Noite do Fado (um concurso de fadistas amadores, em diferentes categorias etárias). Em conseqüência, o país, além do afluxo crescente de clientes nacionais, inicia a partir de meados da década de 50 o turismo estrangeiro que tanto beneficiou a economia:

Esta afluência de frequentadores estrangeiros tenderá a reforçar o uso corrente de expressão "casa típica" ou "restaurante típico" para estes espaços, levando em muitos deles a um reforço ainda mais insistente da decoração carregada de memorabília fadista ou tauromáquica. [...] Esta procura estereotipada do "típico" e a preocupação de oferecerem à clientela estrangeira uma espécie de pot pourri das tradições musicais e coreográficas portuguesas levará varias destas casas de Fado a decidirem incluir nos seus programas artísticos, a par com o Fado, propriamente dito, números avulsos de "folclore" de várias regiões do País. (Vieira Nery, 2004: 228-229)

Desta forma, forjando a imagem do folclore e ressaltando a importância das peculiaridades portuguesas nas programas artísticos, o governo queria atrair turistas. Este facto, não obsta a que apareçam também intérpretes representativos e marcantes para a evolução do género.

O nome mais significativo que imprimiu ao Fado nova dinâmica, impondo-o nacional e internacionalmente foi a lisboeta, Amália Rodrigues. A artista considerada o exemplo máximo do Fado, aclamada como a voz de Portugal e uma das mais brilhantes cantoras do século XX estabeleceu o Fado e o folclore portugués onde jamas se esperaria que eles pudessem chegar. Como podemos ler: «Valorizada pessoal, profissional e socialmente, sabendo escolher o seu repertório e fazendo-se acompanhar pelos melhores guitarristas e violistas, a sua figura vestida de negro entusiasma críticos e público, subjugados pela forte personalidade e pela entrega total, quase dramáti- 
ca, da artista à sua arte» (Sucena, 2008: 283). Amália cantava nas duas Américas, em Àfrica, no Próximo Oriente e no Japão. Projectou o nome de Portugal além-fronteiras e tornou-se, a mensageira da portugalidade. Em 1958 é feita Dama da Ordem Militar de Santiago da Espada, e logo é elevada a Oficial da Ordem Militar de Santiago da Espada (trata-se duma Ordem honorífica Portuguesa que é concedida por mérito literário, científico e artístico). Sem dúvida, com as suas atividades Amália apoiava as autoridades que favoreceram a sua carreira dentro e fora do país. As suas canções tratavam de temas como a saudade, a nostalgia, o ciúme. Eram letras permitidas pela ditadura de Salazar que reprimiram às de problemas sociais, políticos ou da ligação ao cotidiano presente. Aceitavam a passividade dos portugueses e exaltavam a subordinação feminina, a submissão amorosa da mulher e as virtudes da pobreza entre outros. Como pode ser visto numa das canções que a artista celebrizou mundialmente, Casa Portuguesa ${ }^{6}$ :

[...] A alegria da pobreza

está nesta grande riqueza

de dar, e ficar contente.

[...] No conforto pobrezinho do meu lar,

há fartura de carinho.

e a cortina da janela é o luar,

mais o sol que bate nela. (Silveira, 1999: 383)

Por outro lado, Amália Rodrigues, deu ao Fado um fulgor novo. Escolheu a poesia erudita com preferência pela de Luis de Macedo, David Mourão Ferreira e Pedro Homem de Mello (Fria Claridade, Povo Que Lavas No Rio), cantou também os grandes poetas da língua portuguesa como Camões, Bocage. Mesmo um dos seus Fados, Abandono, foi proibido por ser considerado um hino aos que se encontravam presos em Peniche. Convém referir que é difícil classificar a artista claramente. Sendo a mais famosa estrela do Fado, cantava em outras línguas, outros estilos e géneros, letras que não foram do repertorio tradicional propagado pelo regime.

\section{A CHEGADA DA DEMOCRACIA}

Após a morte de Francisco Franco em 1975 e António Salazar em 1970, para além de mudanças políticas podemos falar de novos gostos musicais que dominaram o mundo artístico. A nova burguesia urbana não se sentia refletida no sentimentalismo nos dramas amorosos; mais, o folclore relacionava-se apenas com o antigo regime, com o conservador e tradicionalista. A partir dos anos sessenta, quando já se notava que os governos iam perdendo força e começava a haver mais liberdade, a Copla espanhola e o Fado, tão fomentados pelo folclore pós-guerra viam-se agora como

${ }^{6}$ O poema de Reinaldo Ferreira foi composto em 1950, em Moçambique. Interpretado pela cancionetista angolana Sara Chaves e posteriormente, musicado por Vasco Sequeira e Artur Fonseca. Em 1953 foi gravado por Amália Rodrigues. 
os géneros típicos de uns paises fechados e bolorentos. Por conseqüência, já podemos perceber até que ponto dependiam da ditadura e si os artistas como Lola Flores e Amália Rodrigues devem a sua popularidade ao regime.

Há que constatar que durante o franquismo, em España a verdadeira arte flamenca foi substituída por uma vulgarização, muitas vezes representada pelo folclore. Mostrava-se uma imagem artificial e falsa da realidade interna, mas que atraía o turismo que tanto beneficiaria a economia espanhola, debaixo da máxima de "Spain is diferent". No caso de Portugal, o regime também queria atrair aos turistas e por isso inventou as casas "típicas" do Fado e dominava como modelo o Fado-Canção, de temas relacionados com os estereótipos da tradição bairrista, um estribilho cativante e fácil de memorizar. Tal como a canção espanhola que através do folclore utilizou os parâmetros estéticos próprios da "canção popular" e trivializou os seus conteúdos e formas melódicas, o Fado tendia a ser historicista e identificava-se com a postura passadista. Ambos os géneros construíram um produto de disseminação massiva, tão famoso naquela época, o qual foi utilizado pelas ditaduras de forma demagógica e inclusivamente propagandística. Por isso, ao chegar a democracia, a maioria dos espanhóis e portugueses relacionava o Flamenco com a Copla e o Fado com algo antiquado, bolorento ou atrasado.

Uma das diferenças consiste no que em Portugal os artistas tentavam renovar o Fado, porque no mesmo período do Fado-Canção podemos constatar existência de outros vertentes fadistas, depois de Amália, já nos anos 60 surgiu uma nova geração de fadistas com Carlos do Carmo como representante que emancipou-se do contexto tradicionalista e escolheu o acompanhamento de orquestra para os seus discos; logo aparece tembém o Fado aristocrático cuja função foi reunir os artistas que procuravam recuperar um ideal monárquico legitimista, como exeplo temos o empresário da Taverna do Embuçado, Ferreira Rosa, e finalmente nos anos 70 temos a figura de José Manuel Osório, que em 1970 receberá o Premio Bordalo de Casa da Imprensa «pela originalidade do estilo e por procurar libertar o Fado de temas passadistas》 (Vieira Nery, 2004: 246-247). Em 1971 Portugal abre as portas com o Festival de Rock e o I Festival de Jazz na criação da cultura alternativa, tão oposta a tudo tradicional e que tentava deixar para trás a imagem passadista de Portugal. Apesar destas mudanças «No periodo revolucionário de 1974-1975 o Fado tenderá, na prática, a ser, quase por completo banido da Rádio e da Televisão estatizadas» (Vieira Nery, 2004: 257). Mas o género não se rende e depressa volta ao seu espaço natural, os artistas como Amália Rodrigues e Carlos do Carmo não desaparecerem do mundo do espectáculo e o mesmo espectáculo volta com força e entusiasmo. Surgem novos nomes de refêrencia do Fado como foi o caso do vencedor da Grande Noite do Fado em 1979, Camané. Evidentemente, tenderá de compartir o espaço musical com o fenómeno Rui Veloso, os grupos de rock portugueses, com a Música Pimba, música tradicional rural, música pop e até new age. Ao mesmo tempo a música norte-americana, francesa e britânica começavam a influenciar os portugueses. O Fado tentava ser integrado no repertorio corriente dos novos géneros e estilos: António Variações lança em 1982 um disco com a versão estilzada de Povo que Lavas no Rio, o grupo Madredeus inspira-se no âmbito do Fado. 
Espanha não tentava renovar a Copla, prestava-se mais atenção a novos géneros musicais que se tinham tornado populares. Entre os que tinham importância cabe destacar o pop espanhol, que teve o seu início no final do regime de Franco e popularizou-se graças a cantores como Raphael ou Julio Iglesias. Outro tipo de $p o p$ é o famoso e rítmico Ye-yé, composto por una mescla de twist americano y beat inglês, ao mesmo tempo foi importante a música britânica dos The Beatles ou a norteamericana, em especial o rock and roll. Os anos oitenta marcaram uma nova época musical e cultural em Espanha. O panorama político tinha mudado, a sociedade necessitava ar fresco. Daí surgiu um movimento de contracultura apelidado de "movida madrileña", que desenvolveu a cultura alternativa na capital. Entre os grupos que mais se popularizaram encontram-se os Alaska e os Pegamoides, Mecano, etc. Este movimento teve muita importância para um país que queria afastar-se da imagem da Espanha franquista e concentrar-se na democrática. Como consequência disso, as novas autoridades apoiaram a movida para que lutasse contra a opinião pejorativa que o país tinha adquirido ao longo de quatro décadas de ditadura e, para além disso, para mostrar uma Espanha "moderna".

\section{A MODO DE CONCLUSÃO}

Com todo isto, e tal como temos observado ao analisar o fenómeno do Fado e da Copla, a música desempenharia um importante papel naquela época, de tal modo que os regimes trataram de proteger o seu uso (géneros musicais considerados tipicamente espanhóis e portugueses) como possível barreira para a entrada de elementos externos. Nesse sentido, eram sinais de identidade do espanhol e do português e do "sentir do povo".

Estos géneros viveram uma época de ouro sob o regime e acompanharam mais de uma geração da gente. Os versos, que contavam histórias de amores desfavorecidos, e ocorriam fora do tempo e do espaço, ao mesmo tempo ajudavam ao regime a mudar o pensamento dos cidadãos submissos e a reorganizar a sua vida diária, cheia de dificuldades e problemas. Indubitavelmente, o afluxo crescente de turistas, o relançamento da indústria discográfica e a alargada receptividade de todas as emissoras na rádio e logo televisão influenciaram de forma significativa na popularização dos géneros. Como já dissemos anteriormente, os artistas como Amália e Lola Flores não desapareceram do mundo do espectáculo. Atuavam até à sua morte em programas de televisão e rádio, e foram uns dos temas preferidos da imprensa cor-de-rosa. A diferença é que alguns espanhóis sentiam-se bem representados pela cantora, de tal forma que inclusivamente com a chegada da democracia, Lola Flores foi uma das figuras que mais interesse despertava e continuava sendo uma artista popular e famosa. Há que reconhecer que ela foi o retrato fabricado de uma certa Espanha, em que a copla, "os tablaos" e a "grasia" eram símbolos do país. No caso do Fado, Amália esteve no topo durante décadas e décadas não por seguir a linha do Fado tradicional, senão pelo contrário, por tê-la cambiado e renovado. É verdade que as ditaduras se aproveitaram 
da Copla e do Fado, usaram-nos para os seus fins políticos e propagandísticos, mas os artistas não agradecem a sua popularidade e fama apenas ao regime. Possivelmente, as letras da Copla seguem sendo atadas ao seu bolorento passado da alma quieta, e mostra-se outros estilos Flamencos como representativos, mas no mundo fadista, temos um verdadeiro renascimento do género com artistas como Mísia, Cristina Branco, Mariza, Camané, Katia Guerreiro, Mafalda Arnauth e muitos mais que vão ganhando uma dinâmica imparável de plena consagração. Em virtude do crescente interesse tanto em Portugal como internacionalmente, estamos a lidar com as mudanças que ocorrem em dois níveis paralelos: Fado - a música tradicional, local, desenvolvida por artistas portugueses e Fado como um fenômeno global que pertence ao chamado World Music. Tendo em conta o desenvolvimento e a onipresente globalização vale a pena considerar no futuro a questão dos fatores de internacionalização e o mesmo "sucesso" do Fado e o "interesse" da Copla a fim de compreender o fenômeno do transculturalismo na contemporaneidade.

\section{BIBLIOGRAFIA}

Boyero Gómez, Pilar (2002): La copla: recuperación de un Patrimonio común. $1 .^{a}$ parte. URL: $<\mathrm{http} / / /$ ab.dip-caceres.org/alcantara/alcantara_online/57/57_002a.htm> (14 de maio 2012).

Fromm, Erich (1947): El miedo a la Libertad. Barcelona: Paidós.

GARCía Garzón, Juan Ignacio (2002): Lola Flores. El volcán y la brisa. (2a ed.) Biografías vivas ABC, 24. Madrid: Folio.

Herrero, Fernando (1984): «Folklore y cultura». Revista de Folklore 37: 26-30.

Huici Módenes, Norman Adrián (1996): Estrategias de la persuasión. Mito y propaganda. Sevilla: Alfar.

Llorente Hernández, Angel (1995): Arte e ideología en el franquismo (1936-1951). Madrid: Visor. Mattoso, José (dir.) (1998): História de Portugal, vol. VII. Lisboa: Estampa.

MuÑiz Velázquez, José Antonio (1998): «La música en el sistema propagandístico franquista». Historia y Comunicación Social 3: 343-363.

SilveIRA, Jorge Ferdando (1999): Escrever a casa portuguesa. Belo Horizonte: UFMG.

Stair Sainty, Guy (1997): La Real y Americana Orden de Isabel La Católica. URL:_<http://www. chivalricorders.org/orders/spanish/isabcatl.htm $>$ (19 de maio 2012).

Sucena, Eduardo (2008): Lisboa, o Fado e os Fadistas. Lisboa: Nova Vega.

VÁzQuez MonTALbán, Manuel (1972): Introducción a cancionero general. URL: < http://www.vespito.net/mvm/intcanc.html> (19 de março 2012).

Vieira Nery, Rui (2004): Para uma História do Fado. Lisboa: Público, Corda Seca.

${ }^{7}$ Alguns dos artistas, especialmente Pasión Vega (nascida em 1976) e Diana Navarro (nascida em 1978), tinham "dobrado" e desenvolvido o gênero em direções que começam a ser conhecidas como Nueva Copla ("Novo Copla"), mas ainda não é tão popular como o Fado. 